\title{
PENGARUH BAURAN PEMASARAN DAN KUALITAS PELAYANAN TERHADAP KEPUTUSAN PEMBELIAN PADA GIANT DEPT STORE CABANG CILANDAK JAKARTA
}

\author{
${ }^{1}$ Ahmad Nurhadi, ${ }^{* *}$ Mahnun Mas'adi \\ Universitas Pamulang, Tangerang Selatan, Banten, Indonesia \\ *dosen01017@unpam.ac.id
}

\begin{abstract}
Abstrak
Penelitian ini bertujuan untuk mengetahui pengaruh Bauran pemasaran dan kualitas pelayanan terhadap keputusan pembelian pada Giant Dept Store Cabang Cilandak Jakarta. Metode yang digunakan adalah explanatory research dengan teknik analisis menggunakan analisis statistik dengan pengujian regresi, korelasi, determinasi dan uji hipotesis. Hasil penelitian ini Bauran pemasaran berpengaruh signifikan terhadap keputusan pembelian sebesar 40,3\%, uji hipotesis diperoleh $t$ hitung $>t$ tabel atau $(7,959>1,661)$. Kualitas pelayanan berpengaruh signifikan terhadap keputusan pembelian sebesar 39,0\%, uji hipotesis diperoleh $t$ hitung $>t$ tabel atau $(7,745>1,661)$. Bauran pemasaran dan kualitas pelayanan secara simultan berpengaruh signifikan terhadap keputusan pembelian dengan persamaan regresi $Y=10,956+0,373 X 1+0,363 X 2$ dan kontribusi pengaruh sebesar 49,7\%, uji hipotesis diperoleh F hitung > F tabel atau $(45,585>2,700)$.
\end{abstract}

Kata Kunci: Bauran Pemasaran, Kualitas Pelayanan, Keputusan Pembelian.

\section{Abstract}

This study aims to determine the effect of marketing mix and service quality on purchasing decisions at the Giant Dept Store Cilandak Jakarta Branch. The method used is explanatory research with analysis techniques using statistical analysis with regression testing, correlation, determination and hypothesis testing. The results of this study, the marketing mix has a significant effect on purchasing decisions by $40.3 \%$, hypothesis testing obtained $t$ count $>t$ table or (7.959> 1.661). Service quality has a significant effect on purchasing decisions by $39.0 \%$, hypothesis testing obtained $t$ count $>t$ table or $(7,745>1,661)$. Marketing mix and service quality simultaneously have a significant effect on purchasing decisions with the regression equation $Y=10,956+$ $0,373 X 1+0,363 X 2$ and the contribution of the effect is $49,7 \%$, hypothesis testing obtained $F$ count $>F$ table or $(45,585>2,700)$.

Keywords: Marketing Mix, Service Quality, Purchasing Decision.

\section{PENDAHULUAN}

Pada saat ini meningkatnya penduduk di indonesia mengakibatkan menigkatnya kebutuhan masyarakat. Kebutuhan masyarakat yang sangat beragam tersebut diimbangi dengan munculnya berbagai perusahaan yang memproduksi barang dan jasa, sehingga sekarang ini banyak perusahaanperusahaan yang bergerak dalam jenis usaha yang sama.

Dengan berkembangnnya industri tekstil yang semakin pesat saat ini, membuat konsumen semakin mudah untuk mendapatkan produk yang sesuai dengan kebutuhan dan seleranya. Seiring dengan itu, persaingan di dunia industri tekstil khususnya pakaian pun semakin ketat diantara para produsen yang bersaing dalam memprebutkan konsumen. Oleh Karena itu para produsen terlebih dahulu harus memahami konsumen, mengetahuin apa yang dibutuhkan, apa seleranya, dan melihat bagaimana konsumen mangambil keputusan dalam melakukan pembelian suatu produk.

Untuk sarana pemenuhan kebutuhan sekarang ini, pakaian merupakan pemenuhan yang sangat diperlukan untuk kebutuhan sehariharinya. Pada Tahun 1978, Giant Dept Store hanyalah sebuah store pakaian kecil yang 
terdapat di jalan sabang, Jakarta Pusat. Saat itu, dunia retail belum semarak sepert sekarang. Namun, Giant Dept Store yang berani tampil beda dengan konsep melayani masyarakat kelas menengah ke bawah, mampu menjadi pusat perbeoanjaan idola bagi masyarakat.

Sejak awal, Giant Dept Store konsisten di jalur bisnis garmen dan pakaian jadi. Lalu pada tahun 1985, mereka mulai mendirikan 13 store yang menyediakan beragan kebutuhan dari mulai mainan, stationary, kebutuhan harian dan makanan.

Konsumen menggunakan harga sebagai bahan pertimbangan dalam menentukan pembelian produk-produk atau tidak, kapan sebaiknya pembelian dilakukan serta berapa besar kebutuhan akan produk yang dibeli sesuai dengan kemampuan daya beli konsumen. Suatu produk harus tepat dalam penentuan dan penetapan harga jualnya sehingga dapat diterima oleh konsumen dengan tidak mengabaikan kualitas produk tersebut. Dalam keadaan normal, permintaan dan harga mempunyai hubungan yang negatif atau terbalik dimana semakin tinggi harga ditetapkan semakin kecil permintaan (Jasmani, 2018).

Giant Dept Store memang telah akrab dengan diskon, bahkan diskon tersebut juga memiliki istilah masingmasing seperti Discount time, yang mem berikan potongan harga sebesar 20 persen bagi beberapa produk merk tertentu. Ada juga diskon ala Time Service yang memberikan pelayanan potongan harga sebesar 70 persen secara dengan jangka waktu tertentu.

Agar suatu perusahaan dapat mencapai tujuan jangka panjang, maka menajemen peruhasaan sebaiknya menetapkan terlebih dahulu sarana yang ingin dicapai melalui berbagai strategi pemasran, diantaranya strategi bauran pemasaran dan kualitas pelayanan yang mempengaruhi terhadap keputusan pembeli.

Dengan adanya tahapan-tahapan yang dilewati pembeli untuk mencapai keputusan pembelian, maka produsen perlu pemahaman yang mendalam mangenai konsumen terhadap apa saja yang menjadi pertimbangan konsumen dalam melakukan pembelian satu jenis produk pakaian, karena banyak produsen yang sesungguhnya tidak mengetahui secara tepat mengapa konsumen membeli atau tidak membeli produk yang dihasilkan oleh produsen tersebut. Produsen perlu menyatukan diri mereka secara mendalam kedalam pikiran konsumennya agar dapat lebih mengenal persepsi, nilainya, tingkah laku, kepercayaan dan cara belajar dan tentu saja kebutuhan dan keinginan. Untuk itu skirpsi ini diberi judul "Pengaruh Pengaruh Bauran Pemasaran dan Kualitas Pelayanan Terhadap Keputusan pembelian Pada Giant Dept Store Cabang Cilandak Jakarta".

\section{TINJAUAN PUSTAKA}

1. Bauran Pemasaran

Pemasaran merupakan salah satu faktor yang sangat penting dalam penetuan keberhasilan perusahaan dalam upaya pencapaian tujuannya. Oleh karena itu pengelola pemasaran yang tepat mendapatkan perhatian yang serius dari perusahaan-perusahaan yang telah menyadari akan arti dan pentingnya dari pengelola pemasaran yang baik.

Kegiatan pemasaran yang meliputi perkembangan produk, penentuan harga, pendistribsian, dan promosi perlu dikombinasikan dengan tepat dan optimal agar tercapai penjualan yang maksimal, yang dikenal dengan bauran pemasaran. Bauran pemasaran ini dilakukan oleh manajer pemasaran berdasarkan pasar sasaran dan penentuan posisi produk dipasar sasaran. Kombinasi yang serasi diantara variable-variable bauran pemasaran yang dilaksanakan dengan baik apabila setiap variable memperoleh tingkatan dan posisi yang tepat dan seimbang sesuai dengan posisi yang tepat dan seimbang sesuai dengan posisi produk dan pasar sasaran. 
Menurut Gugup Kismono (2015:308), pengertian marketing mix adalah kombinasi dari variabel atau kegiatan yang merupakan inti dari pemasaran yang terdiri dari strategi produk (product), harga (price), promosi (promotion), dan tempat (place).

2. Kualitas Pelayanan

Memberikan kualitas pelayanan yang baik merupakan hal yang jarang dilakukan oleh perusahaan. Perusahaan yang sangat beroreantasi pada kualitas pelayanan yang baik dapat menciptakan yang baik bagi perusahaan.

Menurut Parusuraman et.al (2017) dalam Wong Sohal (2017) mengemukakan tentang 5 dimensi kualitas pelayanan atau SERQUVAL, dimana instrumen ini dapat digunakan secara umum oleh perusahaanperusahaan jasa didalam mengukur tingkat kualitas pelayanan yang diberikan terdiri dari: Kehandalan, Daya Tanggap, Jaminan, Empati dan Wujud Nyata (Tangible).

Keputusan pembelian

Menurut Ferrinadewi (2014:97) dalam model sikap terbentuk tiga komponen pembentuk sikap dalam kepuasan pelanggan yang terdiri dari komponen: kognitif, afektif, dan konatif.

a. Kognitif adalah pengetahuan dan persepsi pelanggan, yang diperoleh melalui pengalaman dengan suatu objek sikap dan informasi dari berbagai sumber. Pengetahuan dan persepsi ini biasanya berbentuk kepercayaan (belief), yaitu pelanggan mempercayai bahwa produk memiliki sejumlah atribut. Kognitif ini sering juga disebut sebagai pengetahuan dan kepercayaan
pelanggan.

b. Afektif mengambarkan emosi dan perasaan pelanggan menunjukkan penilaian langsung dan umum terhadap suatu produk, apakah produk itu disukai atau tidak disukai; apakah produk itu baik atau buruk.

c. Konatif menunjukkan tindakan seseorang atau kecenderungan perilaku terhadap suatu objek, konatif berkaitan dengan tindakan atau perilaku yang akan dilakukan oleh seorang pelanggan (likelihood or tendency) dan sering juga disebut sebagai intention.

\section{METODE}

Populasi dalam penelitian ini berjumlah 96 responden Giant Dept Store Cabang Cilandak Jakarta. Teknik pengambilan sampling dalam penelitian ini adalah samplel jenuh, dimana semua anggota populasi dijadikan sebagai sampel. Dengan demikian sampel dalam penelitian ini berjumlah 96 responden. Jenis penelitian yang dipakai adalah asosiatif, dimana tujuannya adalah untuk mengetahui pengaruh antara variabel bebas terhadap variabel terikat baik parsial maupun simultan. Dalam menganalisis data digunakan uji instrumen, uji asumsi klasik, regresi, koefisien determinasi dan uji hipotesis.

\section{HASIL DAN PEMBAHASAN}

1. Analisis Deskriptif

Pada pengujian ini digunakan untuk mengetahui skor minimum dan maksimum, mean score dan standar deviasi dari masing-masing variabel. Adapun hasilnya sebagai berikut:

Tabel 1. Hasil Analisis Descriptive Statistics

Descriptive Statistics

\begin{tabular}{ll|r|r|r|r} 
& & & & Std. \\
& $\mathrm{N}$ & Minimum & Maximum & Mean & Deviation \\
\hline Bauran pemasaran (X1) & 96 & 32 & 48 & 38.29 & 3.844 \\
\hline Kualitas pelayanan (X2) & 96 & 30 & 45 & 38.33 & 3.704 \\
\hline Keputusan pembelian (Y) & 96 & 32 & 46 & 39.15 & 3.521 \\
\hline Valid N (listwise) & 96 & & & & \\
\hline
\end{tabular}


Bauran pemasaran diperoleh varians minimum sebesar 32 dan varians maximum 48 dengan mean score sebesar 3,83 dengan standar deviasi 3,844.

Kualitas pelayanan diperoleh varians minimum sebesar 30 dan varians maximum 45 dengan mean score sebesar 3,83 dengan standar deviasi 3,704.

Keputusan pembelian diperoleh varians minimum sebesar 32 dan varians maximum 46 dengan mean score sebesar 3,91 dengan standar deviasi 3,521.
2. Analisis Verifikatif.

Pada analisis ini dimaksudkan untuk mengetahui pengaruh variabel independen terhadap variabel dependen. Adapun hasil pengujian sebagai berikut:

a. Analisis Regresi Linier Berganda

Uji regresi ini dimaksudkan untuk mengetahui perubahan variabel dependen jika variabel independen mengalami perubahan. Adapun hasil pengujiannya sebagai berikut:

Tabel 2. Hasil Pengujian Regresi Linier Berganda

\begin{tabular}{|c|c|c|c|c|c|}
\hline \multirow[b]{3}{*}{ Model } & \multicolumn{3}{|c|}{ Coefficients ${ }^{a}$} & \multirow[b]{3}{*}{$\mathrm{t}$} & \multirow[b]{3}{*}{ Sig. } \\
\hline & \multicolumn{2}{|c|}{$\begin{array}{l}\text { Unstandardized } \\
\text { Coefficients }\end{array}$} & $\begin{array}{l}\text { Standardized } \\
\text { Coefficients }\end{array}$ & & \\
\hline & B & $\begin{array}{l}\text { Std. } \\
\text { Error }\end{array}$ & Beta & & \\
\hline (Constant) & 10.956 & 2.959 & & 3.703 & .000 \\
\hline $\begin{array}{l}\text { Bauran pemasaran } \\
(\mathrm{X} 1)\end{array}$ & .373 & .084 & .407 & 4.446 & .000 \\
\hline $\begin{array}{l}\text { Kualitas pelayanan } \\
(\mathrm{X} 2)\end{array}$ & .363 & .087 & .382 & 4.166 & .000 \\
\hline
\end{tabular}

a. Dependent Variable: Keputusan pembelian $(\mathrm{Y})$

Berdasarkan hasil pengujian pada tabel di atas, diperoleh persamaan regresi $\mathrm{Y}=10,956+$ 0,373X1 + 0,363X2. Dari persamaan tersebut dijelaskan sebagai berikut:

1) Konstanta sebesar 10,956 diartikan jika Bauran pemasaran dan kualitas pelayanan tidak ada, maka telah terdapat nilai keputusan pembelian sebesar 10,956 point.

2) Koefisien regresi Bauran pemasaran sebesar 0,373, angka ini positif artinya setiap ada peningkatan Bauran pemasaran sebesar 0,373 maka keputusan pembelian juga akan mengalami peningkatan sebesar 0,373 point.

Tabel 3. Hasil Pengujian Koefisien Korelasi Bauran pemasaran Terhadap Keputusan pembelian.

\begin{tabular}{|c|c|c|c|}
\hline & \multirow{2}{*}{$\begin{array}{l}\text { Correlations }^{\mathbf{b}} \\
\text { Bauran pemasaran }(\mathrm{X} 1)\end{array}$} & \multirow{2}{*}{$\begin{array}{l}\text { Keputusan } \\
\text { pembelian }(Y)\end{array}$} \\
\hline & & & \\
\hline \multirow{2}{*}{$\begin{array}{l}\text { Bauran } \\
\text { pemasaran }(X 1)\end{array}$} & Pearson Correlation & 1 & $.634^{* *}$ \\
\hline & Sig. (2-tailed) & & .000 \\
\hline \multirow{2}{*}{$\begin{array}{l}\text { Keputusan } \\
\text { pembelian }(\mathrm{Y})\end{array}$} & Pearson Correlation & $.634^{* *}$ & 1 \\
\hline & Sig. (2-tailed) & .000 & \\
\hline
\end{tabular}


Berdasarkan hasil pengujian diperoleh nilai korelasi sebesar 0,634 artinya Bauran pemasaran memiliki

Tabel 4. Hasil Pengujian Koefisien Korelasi Kualitas pelayanan Terhadap Keputusan

pembelian.

Correlations $^{b}$

Kualitas pelayanan $(\mathrm{X} 2) \quad$ Keputusan pembelian $(\mathrm{Y})$

\begin{tabular}{llr|r}
\hline Kualitas pelayanan $(X 2)$ & Pearson Correlation & 1 & $.624^{* *}$ \\
\cline { 2 - 4 } & Sig. (2-tailed) & .600 \\
\hline Keputusan pembelian (Y) & Pearson Correlation & .000 & 1 \\
\cline { 2 - 4 } & Sig. (2-tailed) & & .000 \\
\hline
\end{tabular}

**. Correlation is significant at the 0.01 level (2-tailed).

b. Listwise $\mathrm{N}=100$

Berdasarkan hasil pengujian diperoleh nilai korelasi sebesar 0,624 artinya kualitas pelayanan memiliki

Tabel 5. Hasil Pengujian Koefisien Korelasi Bauran pemasaran dan Kualitas pelayanan secara simultan Terhadap Keputusan pembelian.

\begin{tabular}{|c|c|c|c|c|}
\hline \multicolumn{5}{|c|}{ Model Summary } \\
\hline Model & $\mathrm{R}$ & R Square & Adjusted R Square & Std. Error of the Estimate \\
\hline 1 & $.705^{a}$ & .497 & .486 & 2.525 \\
\hline
\end{tabular}

a. Predictors: (Constant), Kualitas pelayanan (X2), Bauran pemasaran (X1)

Berdasarkan hasil pengujian diperoleh nilai korelasi sebesar 0,705 artinya Bauran pemasaran dan kualitas pelayanan secara simultan memiliki hubungan yang kuat terhadap keputusan pembelian. c. Analisis Koefisien Determinasi

Analisis koefisien determinasi dimaksudkan untuk mengetahui besarnya persentase pengaruh dari variabel independen terhadap variabel dependen baik secara parsial maupun simultan. Adapun hasil pengujian sebagai berikut:

Tabel 6. Hasil Pengujian Koefisien Determinasi Bauran pemasaran Terhadap Keputusan pembelian.

Model Summary

\begin{tabular}{lr|r|r|r} 
Model & $\mathrm{R}$ & R Square & Adjusted R Square & Std. Error of the Estimate \\
\hline 1 & $.634^{\mathrm{a}}$ & .403 & .396 & 2.736 \\
\hline
\end{tabular}

a. Predictors: (Constant), Bauran pemasaran (X1)

Berdasarkan hasil pengujian diperoleh nilai determinasi sebesar
0,403 artinya Bauran pemasaran memiliki kontribusi pengaruh sebesar 40,3\% terhadap keputusan pembelian.

Tabel 7. Hasil Pengujian Koefisien Determinasi Kualitas pelayanan Terhadap Keputusan pembelian.

Model Summary

\begin{tabular}{lrrr|r} 
Model & $\mathrm{R}$ & $\mathrm{R}$ Square & $\begin{array}{r}\text { Model Summary } \\
\text { Adjusted R Square }\end{array}$ & Std. Error of the Estimate \\
\hline 1 & $.624^{\mathrm{a}}$ & .390 & .383 & 2.766 \\
\hline a. Predictors: (Constant), Kualitas pelayanan (X2) &
\end{tabular}

Berdasarkan hasil pengujian diperoleh nilai determinasi sebesar 0,390 artinya kualitas pelayanan memiliki kontribusi pengaruh sebesar $39,0 \%$ terhadap keputusan pembelian. 
Tabel 8. Hasil Pengujian Koefisien Determinasi Bauran pemasaran dan Kualitas pelayanan Terhadap Keputusan pembelian.

Model Summary

\begin{tabular}{lrrrrr} 
Model & $\mathrm{R}$ & $\mathrm{R}$ Square & Adjusted R Square & Std. Error of the Estimate \\
\hline 1 & $.705^{\mathrm{a}}$ & .497 & .486 & 2.525 \\
\hline a. Predictors: (Constant), Kualitas pelayanan (X2), Bauran pemasaran (X1)
\end{tabular}

Berdasarkan hasil pengujian diperoleh nilai determinasi sebesar 0,497 artinya Bauran pemasaran dan kualitas pelayanan secara simultan memiliki kontribusi pengaruh sebesar $49,7 \%$ terhadap keputusan pembelian, sedangkan sisanya sebesar $50,3 \%$ dipengaruhi faktor lain. d. Uji Hipotesis

Uji hipotesis Parsial (Uji t)

Pengujian hipotesis dengan uji $\mathrm{t}$ digunakan untuk mengetahui hipotesis parsial mana yang diterima. Hipotesis pertama: Terdapat pengaruh yang signifikan antara Bauran pemasaran terhadap keputusan pembelian.

Tabel 9. Hasil Uji Hipotesis Bauran pemasaran Terhadap Keputusan pembelian.

\begin{tabular}{|c|c|c|c|c|c|c|}
\hline & \multicolumn{6}{|c|}{ Coefficients ${ }^{a}$} \\
\hline & \multicolumn{3}{|c|}{$\begin{array}{l}\text { Unstandardized } \\
\text { Coefficients }\end{array}$} & \multicolumn{2}{|l|}{$\begin{array}{l}\text { Standardized } \\
\text { Coefficients }\end{array}$} & \multirow[b]{2}{*}{ Sig. } \\
\hline & Model & B & $\begin{array}{l}\text { Std. } \\
\text { Error }\end{array}$ & Beta & $\mathrm{t}$ & \\
\hline \multirow[t]{2}{*}{1} & (Constant) & 16.890 & 2.810 & & 6.010 & .000 \\
\hline & $\begin{array}{l}\text { Bauran } \\
\text { pemasaran } \\
(\mathrm{X} 1)\end{array}$ & .581 & .073 & .634 & 7.959 & .000 \\
\hline
\end{tabular}

a. Dependent Variable: Keputusan pembelian (Y)

Berdasarkan hasil pengujian pada tabel di atas, diperoleh nilai $\mathrm{t}$ hitung $>\mathrm{t}$ tabel atau $(7,959>1,661)$, dengan demikian hipotesis pertama

Tabel 10. Hasil Uji Hipotesis Kualitas pelayanan Terhadap Keputusan pembelian. yang diajukan bahwa terdapat pengaruh yang signifikan atara Bauran pemasaran terhadap keputusan pembelian diterima.

\begin{tabular}{|c|c|c|c|c|c|}
\hline \multicolumn{6}{|c|}{ Coefficients ${ }^{a}$} \\
\hline & $\begin{array}{r}\text { Unsta } \\
\text { Coef }\end{array}$ & $\begin{array}{l}\text { dized } \\
\text { its }\end{array}$ & $\begin{array}{l}\text { Standardized } \\
\text { Coefficients }\end{array}$ & & \\
\hline Model & B & $\begin{array}{l}\text { Std. } \\
\text { Error }\end{array}$ & Beta & $\mathrm{t}$ & Sig. \\
\hline 1 (Constant) & 16.401 & 2.950 & & 5.559 & .000 \\
\hline $\begin{array}{l}\text { Kualitas } \\
\text { pelayanan }(X 2)\end{array}$ & .593 & .077 & .624 & 7.745 & .000 \\
\hline
\end{tabular}

a. Dependent Variable: Keputusan pembelian (Y)

Berdasarkan hasil pengujian pada tabel di atas, diperoleh nilai $\mathrm{t}$ hitung $>\mathrm{t}$ tabel atau $(7,745>1,661)$, dengan demikian hipotesis kedua yang diajukan bahwa terdapat pengaruh yang signifikan atara kualitas pelayanan terhadap keputusan pembelian diterima.
Uji Hipotesis Simultan (Uji F)

Pengujian hipotesis dengan uji $\mathrm{F}$ digunakan untuk mengetahui hipotesis simultan yang mana yang diterima.

Hipotesis ketiga Terdapat pengaruh yang signifikan antara Bauran pemasaran dan kualitas pelayanan terhadap keputusan pembelian. 
Tabel 11. Hasil Uji Hipotesis Bauran pemasaran dan Kualitas pelayanan Terhadap Keputusan pembelian.

\begin{tabular}{|c|c|c|c|c|c|c|}
\hline \multicolumn{7}{|c|}{ ANOVA ${ }^{a}$} \\
\hline & & $\begin{array}{l}\text { Sum of } \\
\text { Squares }\end{array}$ & $\mathrm{df}$ & $\begin{array}{l}\text { Mean } \\
\text { Square }\end{array}$ & $\mathrm{F}$ & Sig. \\
\hline \multirow[t]{3}{*}{1} & Regression & 2 & 292.444 & 45.858 & $.000^{\mathrm{b}}$ & 2 \\
\hline & Residual & 93 & 6.377 & & & 93 \\
\hline & Total & 95 & & & & 95 \\
\hline
\end{tabular}

Berdasarkan hasil pengujian pada tabel di atas, diperoleh nilai $\mathrm{F}$ hitung > F tabel atau $(45,585>2,700)$, dengan demikian hipotesis ketiga yang diajukan bahwa terdapat pengaruh yang signifikan atara Bauran pemasaran dan kualitas pelayanan terhadap keputusan pembelian diterima

\section{PEMBAHASAN HASIL PENELITIAN}

1. Pengaruh Bauran pemasaran Terhadap Keputusan pembelian

Bauran pemasaran berpengaruh signifikan terhadap keputusan pembelian dengan korelasi sebesar 0,634 atau memiliki hubungan yang kuat dengan kontribusi pengaruh sebesar 40,3\%. Pengujian hipotesis diperoleh nilai $t$ hitung $>\mathrm{t}$ tabel atau $(7,959>1,661)$. Dengan demikian hipotesis pertama yang diajukan bahwa terdapat berpengaruh signifikan antara Bauran pemasaran terhadap keputusan pembelian diterima.

2. Pengaruh Kualitas pelayanan Terhadap Keputusan pembelian

Kualitas pelayanan berpengaruh signifikan terhadap keputusan pembelian dengan korelasi sebesar 0,624 atau memiliki hubungan yang kuat dengan kontribusi pengaruh sebesar $39,0 \%$. Pengujian hipotesis diperoleh nilai $t$ hitung $>\mathrm{t}$ tabel atau $(7,745>1,661)$. Dengan demikian hipotesis kedua yang diajukan bahwa terdapat berpengaruh signifikan antara kualitas pelayanan terhadap keputusan pembelian diterima.

3. Pengaruh Bauran pemasaran dan Kualitas pelayanan Terhadap Keputusan pembelian

Bauran pemasaran dan kualitas pelayanan berpengaruh signifikan terhadap keputusan pembelian dengan diperoleh persamaan regresi $Y=10,956+$ $0,373 X 1+0,363 X 2$, nilai korelasi sebesar 0,705 atau memiliki hubungan yang kuat dengan kontribusi pengaruh sebesar $49,7 \%$ sedangkan sisanya sebesar $50,3 \%$ dipengaruhi faktor lain. Pengujian hipotesis diperoleh nilai $\mathrm{F}$ hitung $>\mathrm{F}$ tabel atau $(45,585>2,700)$. Dengan demikian hipotesis ketiga yang diajukan bahwa terdapat berpengaruh signifikan antara Bauran pemasaran dan kualitas pelayanan terhadap keputusan pembelian diterima.

\section{KESIMPULAN DAN SARAN}

Kesimpulan

1. Bauran pemasaran berpengaruh signifikan terhadap keputusan pembelian dengan kontribusi pengaruh sebesar 40,3\%. Uji hipotesis diperoleh nilai t hitung $>\mathrm{t}$ tabel atau $(7,959>1,661)$.

2. Kualitas pelayanan berpengaruh signifikan terhadap keputusan pembelian dengan kontribusi pengaruh sebesar 39,0\%. Uji hipotesis diperoleh nilai thitung $>\mathrm{t}$ tabel atau $(7,745>1,661)$.

3. Bauran pemasaran dan kualitas pelayanan berpengaruh signifikan terhadap keputusan pembelian dengan kontribusi pengaruh sebesar 49,7\% sedangkan sisanya sebesar 50,3\% dipengaruhi faktor lain. Uji hipotesis diperoleh nilai $\mathrm{F}$ hitung $>\mathrm{F}$ tabel atau $(45,585>2,700)$.

\section{Saran}

1. Perusahaan harus memadukan konsep pemasaran yang terpadu dari marketing mix karena faktor-faktor tersebut mampu mendorong pelanggan untuk melakukan keputusan pembelian. 
2. Perusahaan harus memberikan penekanan pada karyawan terkait perilaku yang bersahabat melalui interaksi dari karyawan, serta fasilitas yang memadai dapat memberikan perasaan nyaman kepada konsumen memberikan kualitas pelayanan yang baik merupakan hal yang jarang dilakukan oleh perusahaan. Perusahaan yang sangat berorientasi pada kualitas pelayanan yang baik dapat menciptakan citra yang baik bagi perusahaan.

3. Untuk itu bagi perusahaan harus mengetahui bagaimana perilaku konsumen dalam melakukan keputusan pembelian. Dalam hal ini, agar perusahaan dapat bersaing dimata konsumen, maka perusahaan sebaiknya memperhatikan beberapa fakor yang mempengaruhi keputusan pembelian.

\section{DAFTAR PUSTAKA}

Algifari. (2015). “Analisis Regresi untuk Bisnis dan Ekonomi". Yogyakarta: BPFE.

Edi Sutrisno (2016). Manajemen Sumber Daya Manusia. Jakarta: Prenadamedia Group.

Erlangga, H. (2020). The Challenges of Organizational Communication in the Digital Era. Solid State Technology, 63(4), 1240-1246.

Fandy Tjiptono (2017), Serivce Quality and Satisfiation. Jakarta: Edisi tiga. Andi.

Freddy Rangkuti (2016) Strategi Promosi Yang Kreatif, Edisi Pertama, Cetakan Pertama Jakarta: Gramedia Pustaka Utama

Griffin R.W., \& Ronald, J.E. (2003). DasarDasar Pemasaran. Jakarta: Raja

Haque, MG., Munawaroh, Sunarsi, D., (2020). Analysis of SMEs Culinary Marketing Strategy During Covid 19 Pancemic: A Study at "Sate Bebek Cilegon" Resto in Cilegon, Banten. International Journal of Education, Information Technology, and Others. Vol.3. Issue 2

Imam Ghozali (2017). "Aplikasi Analisis Multivariate Dengan Program SPSS". Edisi Kelima. Semarang: Badan Penerbit Undip.
Jasmani, J. (2018). Pengaruh Kualitas Produk Dan Harga Terhadap Keputusan pembelian Pada PT. Baja Mandiri Di Jakarta. Disrupsi Binis, 1(1).

Kasmad, K., Mustakim, M., \& Sunarsi, D. (2020). Increasing Community School Interest Through Service Quality, Prices and Promotion in Vocational High Schools. Journal of Educational Science and Technology (EST), 6(2).

Keller dan Amstrong (2017) "Prinsip-prinsip Pemasaran". Edisi Kedua Belas". Jilid Satu. Jakarta: Erlangga.

Kotler (2016) "Manajemen Pemasaran". Edisi Keempat belas, Jakarta: PT. Indeks.

Lupiyadi, Rambat (2016) Manajemen Pemasaran Jasa edisi 2, Jakarta : Salemba Empat.

Noryani, Y. B. G., Sari, W. I., Rosini, I., Munadjat, B., Sunarsi, D., \& Mahnun Mas' adi, G. (2020). Did ISO 45001, ISO 22000, ISO 14001 and ISO 9001 Influence Financial Performance? Evidence from Indonesian Industries. PalArch's Journal of Archaeology of Egypt/Egyptology, 17(7), 6930-6950.

Philip Kotler (2017) Manajemen Pemasaran, Edisi Keempat Belas, Jakarta: PT. Indeks.

Sudjana (2014) "Metode Statistika", Bandung: Tarsido.

Sunarsi, D. (2020). Pengaruh Bauran Pemasaran Dan Kualitas Pelayanan Terhadap Kepuasan Konsumen Pada Giant Dept Store Cabang BSD Tangerang. E-Mabis: Jurnal Ekonomi Manajemen dan Bisnis, 21(1). . (2020). Analysis of the Effect of Prices, Promotions and Products on Purchase Interest Impacts on Consumer Satisfaction of VIVO Brand Mobile Phones in South Tangerang Region. Jurnal Ad'ministrare, 7(1), 7382.

Yusuf, A., \& Sunarsi, D. (2020). The Effect of Promotion and Price on Purchase Decisions. Almana: Jurnal Manajemen dan Bisnis, 4(2), 272-279. 